\title{
Two Anti-anxiety Drugs: A Psychoneuroendocrine Study
}

\author{
O. O. OGUNREMI, LIISI ADAMSON, VLASTA BŘEZINOVÁ, W. M. HUNTER, A. W. MACLEAN, \\ I. OSWALD, I. W. PERCY-ROBB
}

Introduction

There is an increasing use of drugs that relieve anxiety and promote sleep. In England and $W$ ales there were 10.8 million prescriptions for these drugs in 1965 but 17.2 million in 1970 (Parish, 1971). In an investigation of their human pharmacology we report effects of the chronic use by volunteers of sodium amylobarbitone and of a modern minor tranquillizer, benzoctamine, on plasma growth hormone, plasma corticosteroid concentration, sleep, anxiety, and other variables. The most consistent and largest single component of the total daily secretion of growth hormone (GH) occurs during sleep with E.E.G. slow waves, known as stages 3 and 4 sleep (Sassin et al. 1969). Some hypnosedatives, notably some of the benzodiazepines, such as flurazepam (Kales et al., 1971), strongly suppress these stages of sleep and it was this that prompted the study of endocrine function in sleep.

\section{Subjects and Methods}

A balanced cross-over study was conducted with eight healthy males aged 20-26. Only with the last four of the eight were complete double-blind conditions achieved. These four subjects received specially manufactured sealed capsules, one

Department of Psychiatry, University of Edinburgh, Royal Edinburgh Hospital, Edinburgh EH10 SHF

O. O. OGUNREMI, M.B., D.P.M., (Present appointment: Lecturer, Department of Psychiatry of Úniversity of Ife, Ile-Ife, Western State, Nigeria)

ment of Psychiatry of University of Ife, IR,- Re, Wearch Fellow
LIISI ADAMSON, LICENTIATB N MEDICINE, Reser.
VIASTA BREZINOVA, M.D., PH.D., Research Psychiatrist

IAN OSWALD, M.D., D.SC., Reader in Psychiatry

A. W. MACLEAN, M.A., PH.D. (Present appointment: Associate Professor, Department of Psychology, Queen's University, Kingston, Ontario, Canada)

Medical Research Council Clinical Endocrinology Research Unit, Edinburgh EH1 2QW

W. M. HUNTER, B.SC., PH.D., Member of Scientific Staff

Department of Clinical Chemistry, University of Edinburgh, Royal Infirmary of Edinburgh, Edinburgh

I. W. PERCY-ROBB, M.B., M.R.C.PATH., Senior Lecturer

small capsule three times daily and a larger one at bedtime throughout the first 11 weeks, then after a five-week break they resumed the capsules for another 11 weeks. The actual content of the capsules in each 11-week run was: placebo, three weeks; half-dose of drug, one week; full dose of drug, four weeks; and placebo, three weeks. Subjects who received benzoctamine in their first 11 weeks received sodium amylobarbitone in their second 11 -week period and vice versa.

The dosage of benzoctamine used for all eight subjects was $2.5 \mathrm{mg}$ thrice daily plus $20 \mathrm{mg}$ at night for the half-dosage week, then $5 \mathrm{mg}$ thrice daily and $40 \mathrm{mg}$ at night. Two different dosage scales were used for sodium amylobarbitone. Four men received $12.5 \mathrm{mg}$ thrice daily and $100 \mathrm{mg}$ at night for a week followed by $25 \mathrm{mg}$ thrice daily and $200 \mathrm{mg}$ at night. The other four men received twice as much, two of them being among the first four studied and two among the last.

In each 11-week period the subjects attended the laboratory in the evening and slept in comfortable, sound-attenuated bedrooms in the initial three-week placebo period for a total of seven nights, of which three were "catheter" nights (see below). The first two nights were treated as adaptation nights only, another night served as a catheter adaptation night, two nights provided solely baseline electrophysiological data about sleep, and two catheter nights provided in addition baseline hormone data. In the half-dosage week there was one adaptation night, as also in the third drug-week on full dose. In the first and in the fourth full-dose weeks there were two nights of sleep recording, of which one was a catheter night in each case. In the first withdrawal week on placebo capsules there was one catheter and four other nights, in the next week one adaptation night, and in the final week one catheter and one other night. Oral iron supplements were given throughout.

On all nights silver electrodes placed above and below each outer canthus provided two channels of bipolar eye movement recording, a pair of parieto-occipital electrodes provided one channel of the E.E.G., and a pair of submental electrodes monitored muscle tone, with a paper speed of $15 \mathrm{~mm} / \mathrm{sec}$. On the catheter nights, in addition to the electrophysiological recording, blood was sampled once before sleep and half-hourly during sleep (not in periods of wakefulness) by means of a catheter in a forearm vein. The catheter extension had redundant loops, allowing freedom of movement. It passed through the bedroom wali so that subjects should not be disturbed at sampling times, and after each sample it was refilled with a predetermined volume of saline to which heparin had been added, 20,000 IU/1. Blood samples were centrifuged and the plasma was stored in a deep freeze until assay. Electrophysiological records were stored and eventually scored "blind" for each 20-second epoch in terms of the stages of sleep (Rechtschaffen and Kales, 1968), transitions between stages, and periods of wakefulness. The raw scores were further analysed by computer to give amounts and distributions of stages and events and the data then obtained were used in the final analysis of results. When the distribution of, for example, intra-restlessness was examined in terms of the successive hours of sleep, this meant completed hours of sleepfor instance, the first hour may not be completed until 63 minutes after falling asleep if it is interrupted by three minutes of wakefulness.

Self-ratings of subjective anxiety during the day were made each evening of the 11-week periods by the last four ("blind") subjects. They made a mark each evening at whatever point 
they felt appropriate on a 10-cm line which was marked at the left-hand end "terrible agitation" and on the right "imperturable tranquillity," indicating how calm or anxious they had felt during the day. Similarly each evening they indicated how well they had felt able to concentrate mentally during the day (Oswald et al., 1971). Scores were given by the number of millimetres from the left-hand end of the line to the mark made.

The plasma corticosteroid concentrations were assayed by the method of Mattingly (1962). GH was assayed by radioimmunoassay using an Analmatic preparation unit (Baird and Tatlock Ltd.) to make appropriate dilutions of the plasma over the range $1 / 4$ to $1 / 64$. The separation of bound from free labelled hormone was by a double antibody precipitation system which was indifferent to the presence of human plasma over the range $0-25 \%$. The values used in this report are the means of the responses falling within the steep central portion of the dose-response curve. The standard used was M.R.C. GH Standard A. All samples from all of the studies on any one subject were run in the same assay.

Data from assays were treated in two ways. (1) Mean values across subjects were obtained for each half hour and for each experimental condition. (2) Graphs were plotted for each night and the area under each curve between midnight and 06.30 hours measured and expressed in $\mathrm{cm}^{2}$. Mean areas were then examined in relation to the experimental conditions.

\section{Results}

We outline below only those results which appear of general interest.

\section{ANXIETY AND CONCENTRATION}

The step-wise introduction of drug had little effect on the self-ratings but the resumption of placebo capsules after either drug resulted in feelings of anxiety and concomitant inability to concentrate, as figs. 1 and 2 show for solium amylobarbitone.

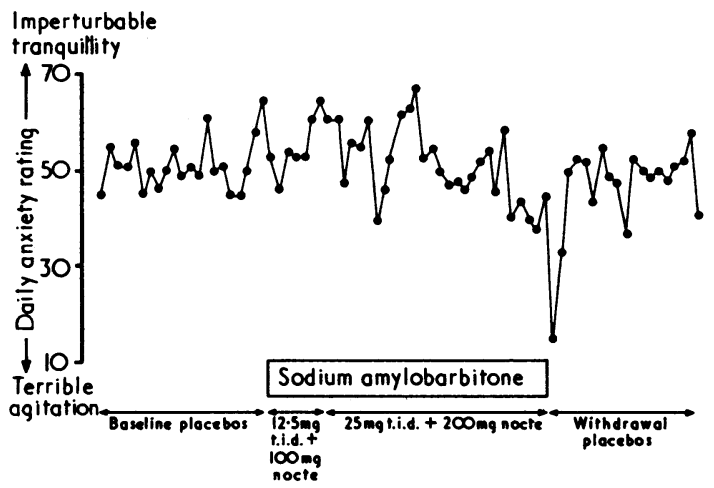

FIG. 1-Barbiturate-induced anxiety in a healthy man.

\section{SLEEP}

Sleep was less restless during administration of both drugs in that the frequency of transitions into wakefulness or stage 1 sleep (drowsiness) was diminished. In the case of benzoctamine there was no evidence of withdrawal rebound (fig. 3) and the same was true of the smaller dose of sodium amylobarbitone, though with the larger dose there was a rebound increase maximal on the third withdrawal night.

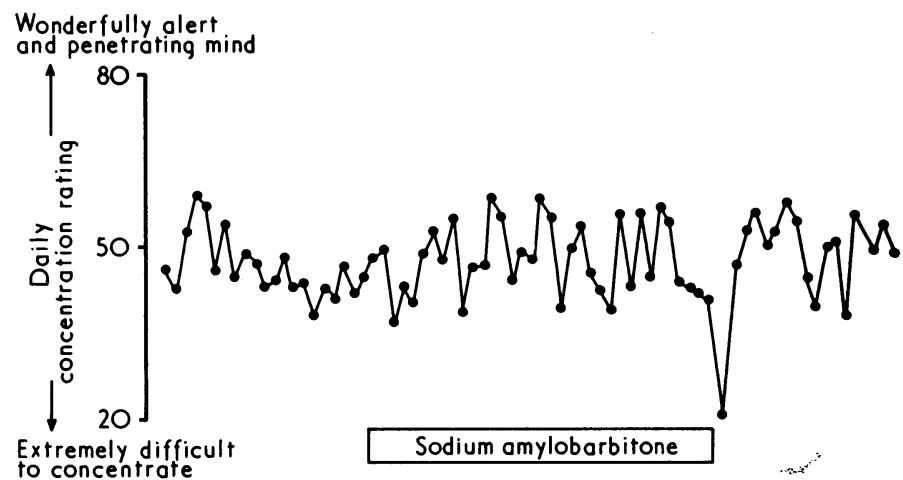

FIG. 2-Inability to concentrate caused by withdrawal after five weeks of sodium amylobarbitone. Means for four men (both dosages).

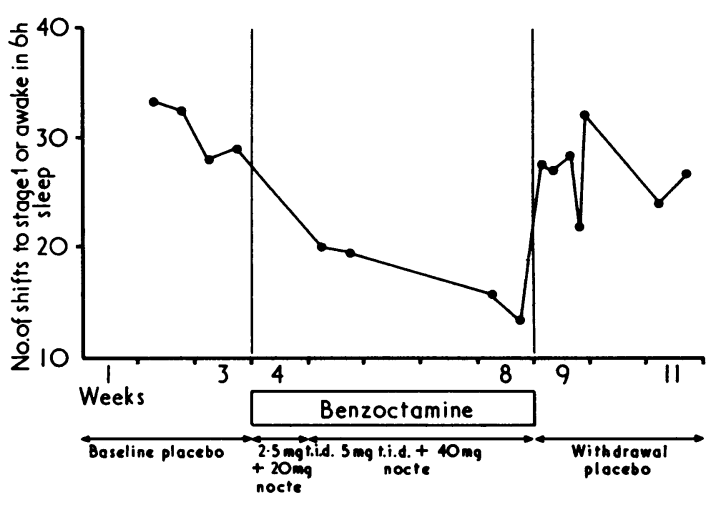

FIG. 3-Intrasleep restlessness was reduced by benzoctamine. No withdrawal rebound. Each point is a mean for eight men.

Early in the five-week drug period the diminution of restlessness was present throughout the night with both drugs, and this was true of benzoctamine in the fifth drug week, but in the case of sodium amylobarbitone a tolerance effect was observed so that although restlessness was still reduced in the early night the late night became more restless in the fifth week than it was during the baseline period (fig. 4).

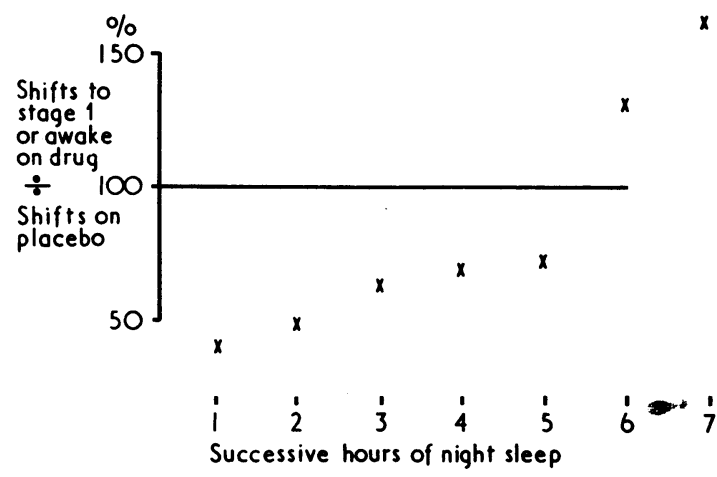

FIG. 4-Early-night restlessness is reduced but late-night restlessness is increased by larger dose of sodium amylobarbitone in fifth week of administration. Data are from four men. Values from means of their four baseline nights (in that half of the experiment) are represented as $100 \%$ for each successive hour and the mean scores for their two nights in the fifth drug week are then represented hourly as a proportion of the baseline values.

Slow wave sleep stages 3 and 4 were not altered in duration or distribution during the five weeks of benzoctamine but on withdrawal they at once fell sharply to their two lowest means among the 15 nights. On the other hand the larger dose of sodium amylobarbitone appeared slightly to suppress 
these sleep stages and after both dosage schedules a sharp rise above baseline occurred and persisted into the third withdrawal week (fig. 5). Paradoxical (rapid eye movement) sleep showed reduced duration with sodium amylobarbitone and subsequent withdrawal rebound, while a slight reduction was also apparent with benzoctamine, followed by an immediate withdrawal rebound above baseline. The usual barbiturateinduced fast activity at about $20 \mathrm{~Hz}$ in the E.E.G. was seen during drowsiness and paradoxical sleep after sodium amylobarbitone, and similar fast E.E.G. waves were caused by benzoctamine and persisted into the second withdrawal night.

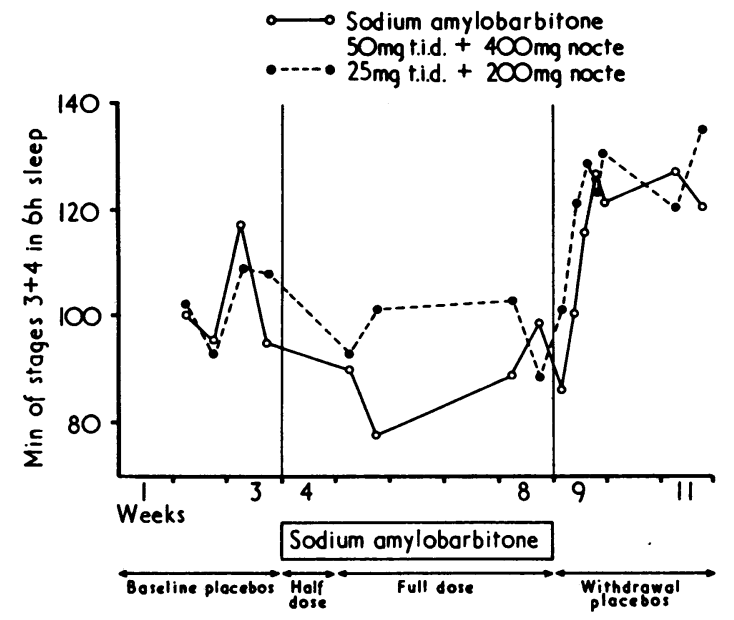

FIG. 5-Duration of sleep stages $3+4$ during and after sodium amylobarbitone. Each point is a mean for four men.

Data from catheter nights have been included above with those from non-catheter nights, but it was of interest to look for possible disturbing effects of the blood-sampling procedures. There were no effects on the distribution of intrasleep restlessness (fig. 6) or on stages $3+4$ sleep. A small effect on paradoxical sleep was, however, apparent. The mean duration on the 32 baseline placebo catheter nights was $63.1 \mathrm{~min}$ in the first six hours of sleep against 71.8 for the 32 noncatheter nights, which proved significant on analysis of variance.

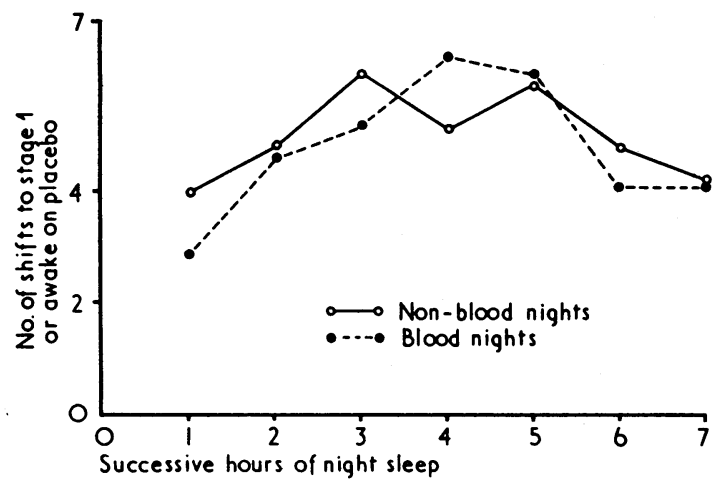

FIG. 6-Intrasleep restlessness is similar on nights with and without blood-sampling. Means for eight men from 32 placebo blood nights and 32 placebo non-blood nights, baseline periods.

\section{GROWTH HORMONE}

The peak of $\mathrm{GH}$ in the early sleep hours was raised after withdrawal of benzoctamine (fig. 7) or of either dosage of sodium amylobarbitone (figs. 8 and 9) even though we did not observe a fall during drug administration. The peak returned to normal by the third withdrawal week.

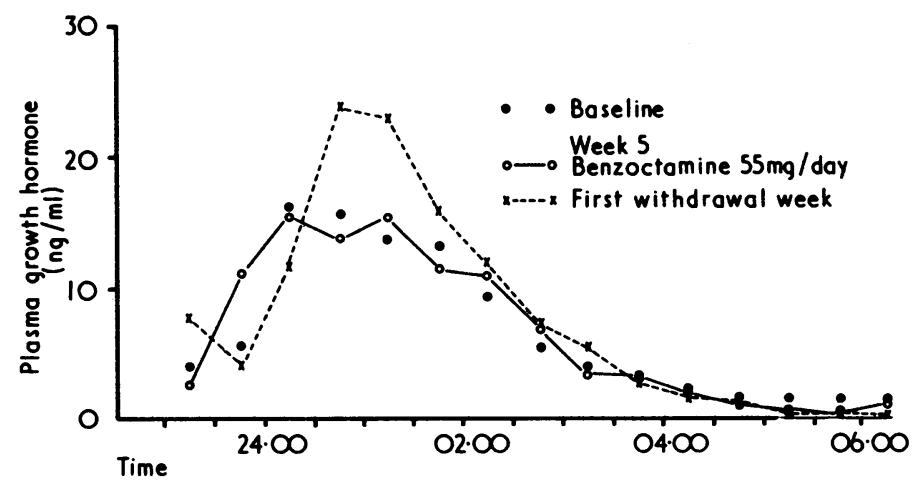

FIG. 7-Growth hormone peak in sleep was higher after benzoctamine withdrawal. Means for eight men.

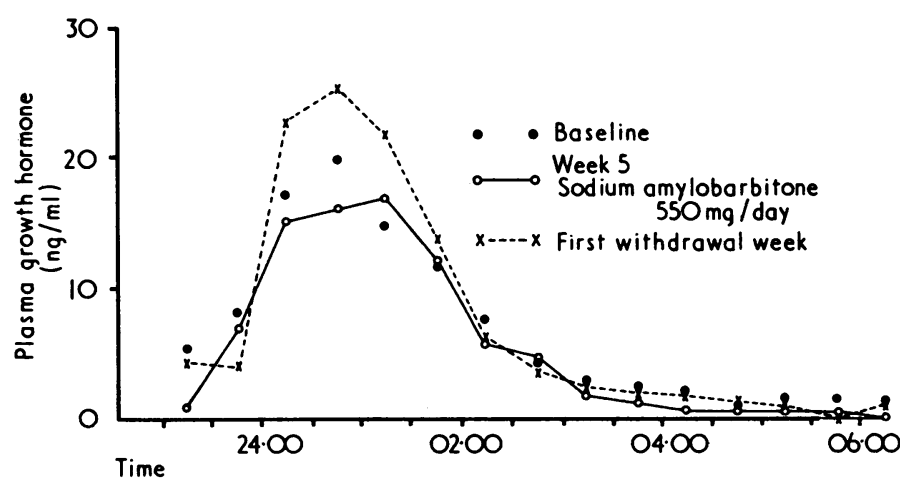

FIG. 8-Growth hormone peak was higher after withdrawal of sodium amylobarbitone (large dose). Means for four men.

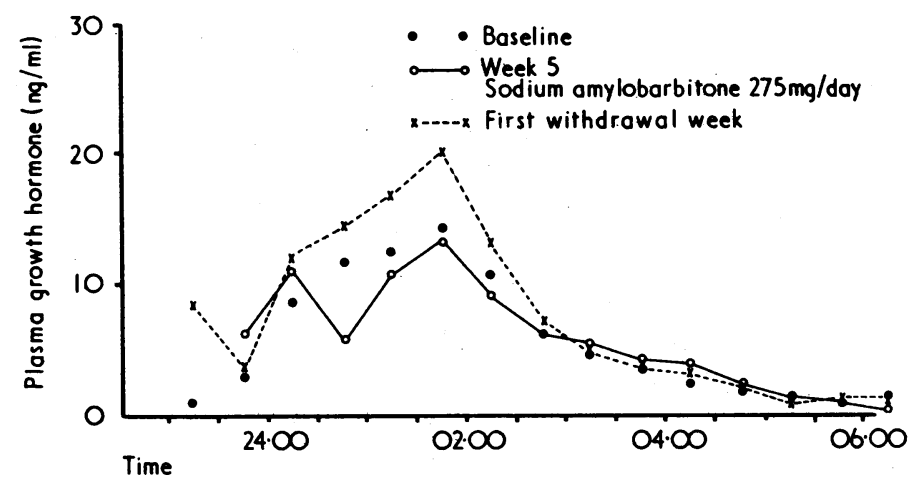

FIG. 9-Growth hormone peak was higher after withdrawal of sodium amylobarbitone (small dose). Means for four men.

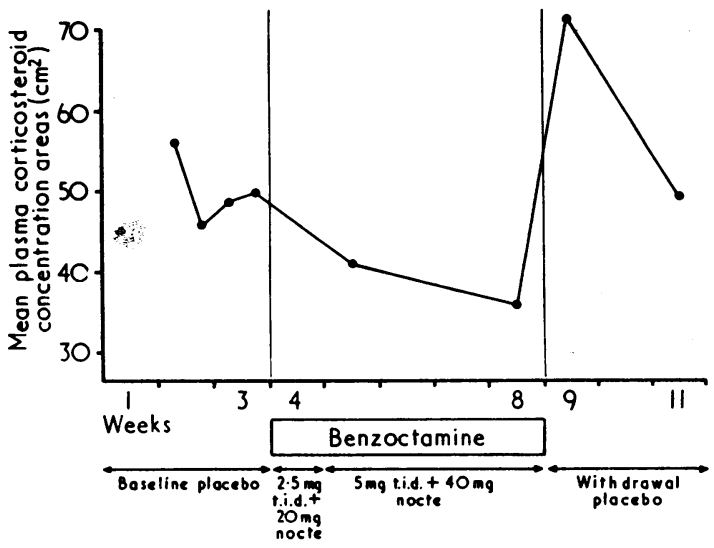

FIG. 10-Nocturnal plasma corticosteroid concentrations, arbitrary units for areas under curves between 24.00 hours and 06.30 hours. Means for eight men. Nights from both halves of study are all included in four baseline values. 


\section{PLASMA CORTICOSTEROID}

Drug administration was associated with lower plasma corticosteroid concentrations and there was a withdrawal rebound above baseline. In the case of benzoctamine the mean areas under the curves for the early and late drug periods were significantly lower than baseline on analysis of variance and the rebound was significantly above baseline (fig. 10). The effect was spread across the night (fig. 11). The findings for the smaller groups of subjects on sodium amylobarbitone did not reach significance but gave curves closely similar to those of fig. 11.

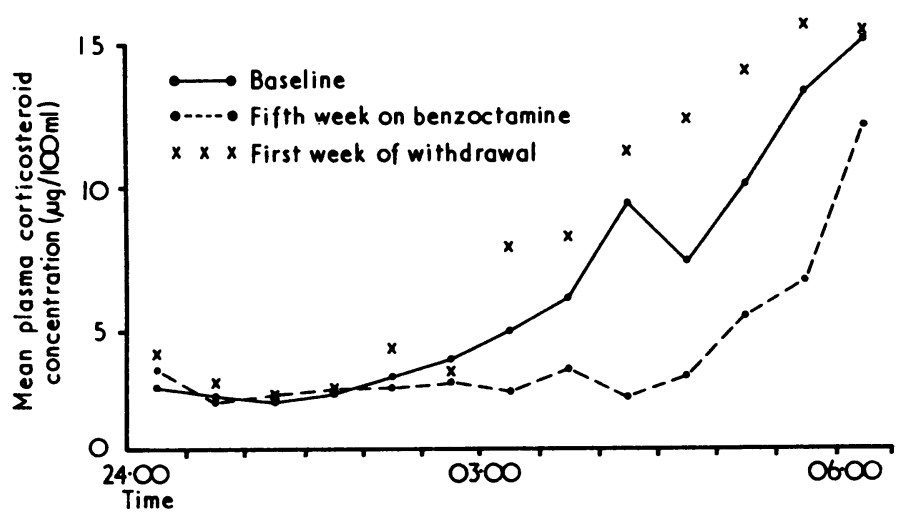

FIG. 11-Plasma corticosteroid concentration in each half hour during benzoctamine and after its withdrawal. Means for eight men.

\section{Discussion}

Forty years ago Kleitman and his colleagues reported that the traditional minor tranquillizer, alcohol, caused nocturnal restlessness to be reduced in the early night but greater than normal in the late night (Mullin et al., 1933). The same phenomenon is seen during chronic use of sodium amylobarbitone, as shown in fig. 4. We looked for this phenomenon in our data because of the clinical observation that patients on such drugs complain of especially poor sleep in the late night. They may find in this a confirmation of their supposed need for an hypnotic at a time when the hypnotic itself is perpetuating the poor sleep.

The phenomenon shown in fig. 4 can be interpreted as a late-night withdrawal rebound as the bedtime dose of drug is metabolized. Comparable intranight rebounds during sleep have been described for paradoxical sleep after evening amphetamine derivatives (Oswald, 1970).

The large, sleep-linked secretion of growth hormone is related in time to E.E.G. slow wave sleep stages $3+4$ (Sassin et al., 1969a, 1969b). In this study there was some reduction and then rebound of stages $3+4$ sleep caused by sodium amylobarbitone but not by benzoctamine, and yet both drugs were followed by raised $\mathrm{GH}$ peaks on withdrawal, suggesting a lack of precise correlation of $\mathrm{GH}$ with the duration of the sleep stages. Slight suppression of stages 3 and 4 sleep has been previously noted with barbiturates (Kales et al., 1970).

There is a relation between anxiety and adrenocortical activity (Johns et al., 1971), raised plasma corticosteroid con- centration being commonly interpreted as an indication of a "stress" reaction. It is therefore of interest that anxietyrelieving agents do lower plasma corticosteroid concentrations and that signs of a stress reaction should be apparent in the withdrawal phase even while the patient is asleep, an observation of relevance to the nightmares that feature at this withdrawal time (Oswald and Priest, 1965; Kales and Jacobson, 1967; Hartmann, 1970). The evidence that two major hormones, both subject to hypothalamic-pituitary control, are greatly influenced by intake and withdrawal of minor tranquillizers serves as a reminder that such drugs can have farreaching if rarely considered actions.

Fraser et al. (1956) reported that withdrawal of $400 \mathrm{mg}$ of a daily barbiturate could cause some anxiety, and fig. 11 shows how even a small dose of $275 \mathrm{mg}$ daily of sodium amylobarbitone may lead to an anxiety reaction. It is thus possible to understand how people who take these drugs or alcohol may have a panic attack or be liable to episodic anxiety as a consequence of their drug or alcohol intake, especially if it is irregular as it so often is in the clinical situation. They may then turn for relief to the very agents that have contributed to their anxiety. Our experiments serve as a reminder that though anxiety-relieving, sleep-promoting drugs can be of great clinical value it would be logical to restrict their use to those patients in whose case an eventual termination of the causes of current anxiety can confidently be foreseen, so rendering easy the eventual withdrawal of the drug.

The research received financial support from Edinburgh University which had received a donation from Ciba-Geigy (U.K.) Ltd. A grant from the Scottish Home and Health Department also assisted. We are grateful to Dr. R. Rondel and Dr. S. A. Lewis for their help. The research described is incorporated in Dr. Ogunremi's submission to London University for the M.D. degree.

Requests for reprints should be addressed to: Dr. I. Oswald, University Department of Psychiatry, Royal Edinburgh Hospital, Edinburgh EH10 5HF.

\section{References}

Fraser, H. F., et al. (1956). Federation Proceedings, 15, 423.

Hartmann, E. (1970). In Sleep and Dreaming, ed. E. Hartmann. Boston Little, Brown.

Johns, M. W., Gay, T. J. A., Masterton, J. P., and Bruce, D. W. (1971). Psychosomatic Medicine, 33, 499.

Kales, A., and Jacobson, A. (1967). Experimental Neurology, Suppl. No. 4, p. 81.

Kales, J., Kales, A., Bixler, E., and Slye, E. S. (1971). Clinical Pharmacology and Therapeutics, 12,691 .

Kales, A., Preston, T. A., Tan, T. L., and Allen, C. (1970). Archives of General Psvchiatrv, 23, 211 .

Mattingly, D. (1962). Fournal of Clinical Pathology, 15, 374

Mattingly, D. (1962). Fournal of Clinical Pathology, 15, 374.1933). American fournal of Physiology, 106, 478 .

Oswald, I. (1970). In Amphetamines and Related Compounds, ed. E. Costa and S. Garattini. New York, Raven Press.

Oswald, I., Lewis, S. A., Dunleavy, D. L. F., Brezinova, V., and Briggs, M. (1971). British Medical fournal, 3, 70.

Oswald, I., and Priest, R. G. (1965). British Medical fournal, 2, 1093

Parish, P. A. (1971). Fournal of the Royal College of General Practitioners, 21, Suppl. No. 4.

Rechtschaffen, A., and Kales, A. (editors) (1968). Manual of Standardized Terminologv, Techniques and Scoring System for Sleep Stages of Human Subiects. Washington, D. C., U.S. Government Printing Office.

Sassin, I. F., et al. (1969a). Science, 165, 513.

Sassin, J. F., et al. (1969b). Life Sciences, part I, 8, 1299. 